\title{
GENETIC PROGRAMMING BASED MODELING OF SHEAR CAPACITY OF COMPOSITE BEAMS WITH PROFILED STEEL SHEETING
}

\author{
M. A. Köroğlu ${ }^{1, *}$, A. Köken ${ }^{1}$, M. H. Arslan ${ }^{1}$ and A. Çevik ${ }^{2}$ \\ ${ }^{1}$ Department of Civil Engineering, Selcuk University, 42075 Konya/TURKEY \\ ${ }^{2}$ Department of Civil Engineering, University Of Gaziantep, 27310/TURKEY \\ *(Corresponding author: E-mail: makoroglu@selcuk.edu.tr)
}

Received: 27 July 2010; Revised: 16 September 2010; Accepted: 20 September 2010

\begin{abstract}
This study investigates the availability of Genetic Programming (GP) for modeling the ultimate shear capacity of composite beams with profiled steel sheeting for the first time in literature. Experimental data involving push-out test specimens of 46 composite beams from an existing database in the literature were used to develop GP model. The input parameters affecting the shear capacity were selected as stud position (strong and weak), sheeting type (width of rib of the profiled steel sheeting, depth of the rib), stud dimensions (height and diameter), slab dimensions (width, depth and height), reinforcement in the slab and concrete compression strength. Moreover, a short review of well-known building codes regarding ultimate shear capacity of composite beams is presented. The accuracy of the codes in predicting the ultimate shear capacity of composite beams was also compared with the proposed GP model with comparable way by using same test data. The study concludes that the proposed GP model predicts the ultimate shear capacity of composite beams by far more accurate than building codes.
\end{abstract}

Keywords: Shear connection, composite beams, push-out tests, genetic programming

\section{INTRODUCTION}

The composite behavior of two or more structural members joined together by using different materials is called "a composite structure". Each material of a composite structure usually has a superior property effectively used for providing the composite behavior of the materials. Although several materials are used as the shear connector of a composite structure, "headed stud" shear connectors are generally used in constructions due to their practicality.

In the composite beams with profiled steel sheeting many factors such as; dimensions and direction of profiled steel sheeting, compressive strength of concrete, reinforcement area and position and also strength, dimension and location of shear connectors affect the behavior of shear connectors. Push out tests is commonly used to determine the capacity of the shear connectors and load-slip behavior of shear connectors. According to Eurocode 4 [1], the push-out specimens consist of a steel beam section held in the vertical position by two identical concrete slabs. The concrete slabs are attached to the beam by shear connectors. The connection is subjected to a vertical load, which produces a shear load along the interface between the concrete slab and the beam flange on both sides. At a specified load or displacement the slip between the slabs and the beam flange is evaluated. The failure load divided by the numbers of the connectors is assumed as the shear connection capacity [2].

Composite construction using steel and concrete has been used since the early 1920s. It gained widespread use in bridges in the 1950s and in buildings in the 1960s [3]. Both push-out tests, which were first used in Switzerland in the 1930s [4], and full-scale beam tests have been used to develop shear stud strength prediction expressions. Push-out tests are usually used to evaluate a wide array of parameters because of the large size and expense of beam tests. 
Early shear stud strength prediction equations were for solid slab construction, the equations developed in the 1960s and 1970s were based on the results of push-out tests. The equations were modified for the use of steel deck in the late 1970s and were based on full-scale beam tests [5]. The stud strength equations given by Grant et al [6] were developed from tests mostly using deck without stiffeners where the studs were welded in the center of the deck rib. Beside the commonly used headed studs, to obtain optimum solutions for composite action, some investigations have done with different type of welded shear connectors like, perfobond, $\mathrm{T}$ connector, horseshoe, bar connector etc... in the previous studies.

There are many variables affecting the shear capacity of composite beams such as stud position (strong and weak), sheeting type (width of rib of the profiled steel sheeting, depth of the rib), stud dimensions (height and diameter), slab dimensions (width, depth and height), reinforcement in the slab and concrete compression strength. The effect of these variables on the shear capacity of composite beams has been extensively studied and some empirical approach has been developed related to variables. For instance, Zellner [7], Veldanda \& Hosain [4], Klaiber \&Wipe [8] and Valente \& Cruz [9] in the area of composite beams with perfobond ribs. Galjaard and Walraven [10] performed tests using shear studs, Perfobond connectors, T-connectors and oscillating Perfobond connectors, both with normal weight and lightweight concrete. Johnson and Oehlers [11] analyzed 125 push-out test results from 11 sources, performed 101 new push-out tests and four composite T-beam tests, and performed a parametric study. And also Köroğlu [12] conducted 4 push-out tests to study the behavior of Turkish extra seismic reinforcement steel bars as shear connector in composite beams with profiled steel sheeting perpendicular to beam. In addition, Köroğlu also performed 4 push-out tests with the headed shear connectors as shear connector to compare the Turkish extra seismic reinforcement steel bars versus headed shear connectors as shear connector $[13,14]$. In Figure 1. test specimen of a composite beam with profiled steel sheeting perpendicular to beam prepared by Köroğlu [12] is given. And also, in Figure 2 the application of the shear connectors from the existing buildings is shown [15].

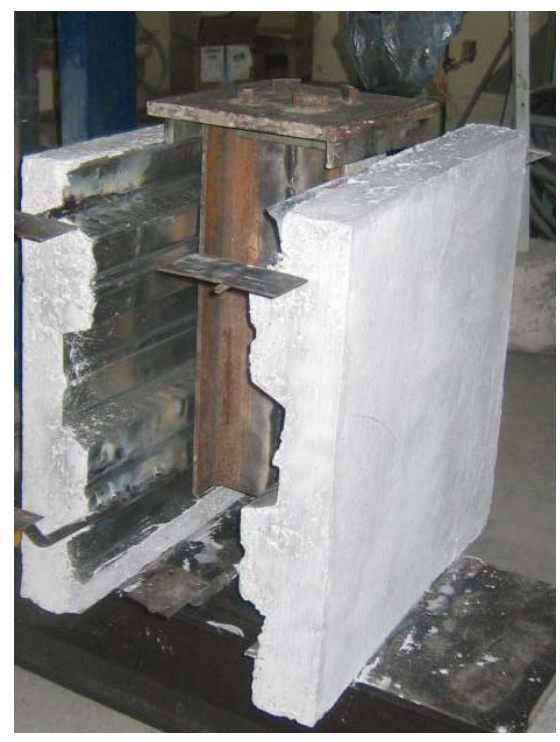

Figure 1. A Photo of a Specimen Prepared for the Push-out Tests [12] 

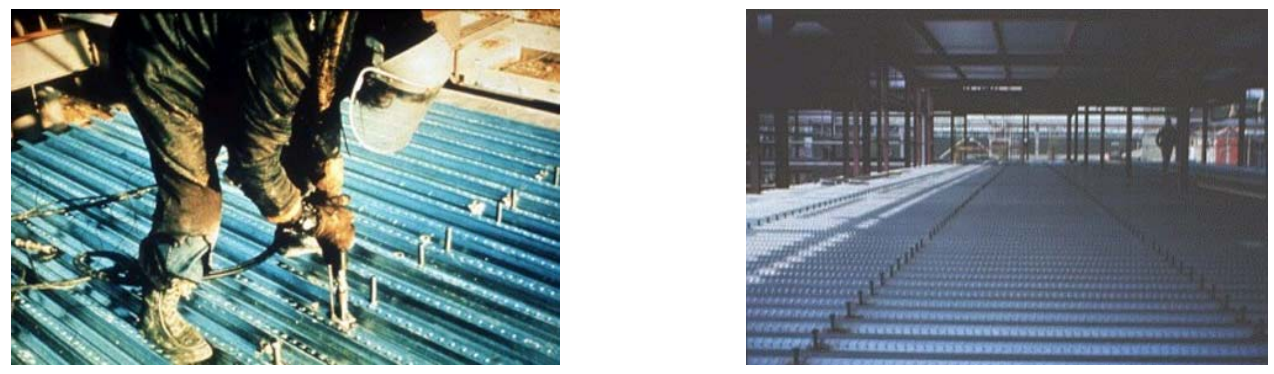

Figure 2. Photos from Application of the Shear Connectors from the Existing Buildings [15]

Because of an enormous variety of shear connectors, strength and ductility of shear connectors are suggested to be determined experimentally. So, because of fast automatic welding procedure headed stud shear connectors are commonly used to ensure composite action. Since it is certainly the most investigated and understood form of shear connection, it is probably the most common form of welded shear connection.

The scope and objectives of the present work are a) to investigate the applicability of Genetic Programming (GP) in predicting the ultimate shear capacity of composite beams by using experimental results collected from the literature, $b$ ) to discuss the effect of the selected parameters on to the shear strength. In this sense, experimental data of 46 composite beams with headed stud shear connectors subjected to push out tests were used from existing databases of Roddenbery [5], Lloyd \& Wright [16], Kim et al [17] and Köroğlu [12]. The experimental database is given in Table Appendix. Furthermore, some code' approaches as AISC [18], Eurocode-4 [1], BSI-BS 5950 [19] and CSA [20] are also examined by comparing their predictions with mentioned experimental studies results. The results obtained by the proposed ANN model and the codes are compared with each other.

\section{CALCULATING SHEAR CAPACITY OF COMPOSITE BEAMS WITH PROFILED STEEL SHEETING}

The design strength and stiffness of composite beams with profiled steel sheeting depends on the shear connection behavior. According to the experimental studies, the main depending factors defining the strength of shear connectors are:

a) Shape and dimensions of the shear connectors,

b) Quality of its material,

c) Concrete strength,

d) Type of load (static and dynamic),

e) Way of connecting the steel beams,

f) Distance between the shear connectors,

g) Dimensions of the concrete slab (see Figure 3.),

h) Percentage and way of reinforcing

i) Sheeting type and dimension of steel sheeting (see Figure 3.),

In the literature, several formulations have been proposed by various researchers. The review of these theories is given in Table 1 . 


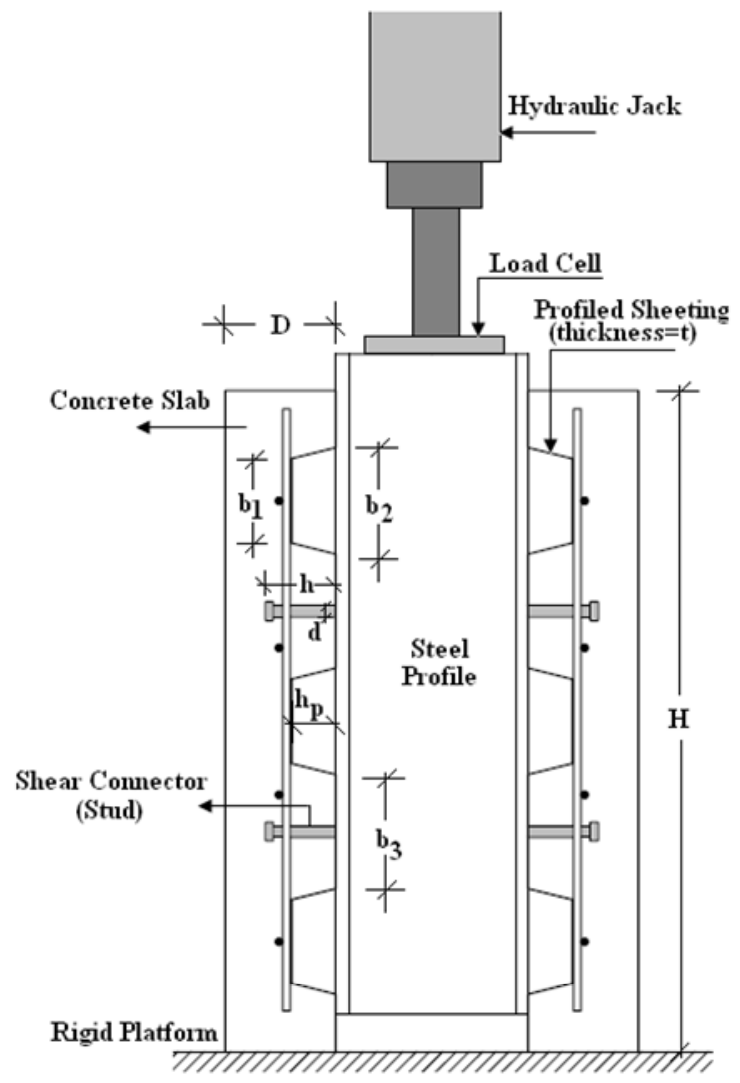

Figure 3. Test Setup, Dimension of Concrete Slab and Steel Sheeting

Early tests by Fisher [21] were performed and several conclusions were drawn regarding the design of composite beams with formed metal decks. An equation for stud connector strength is given as Equation 1. Grant et al [6] was made a modification to the equation developed by Fisher [21] including the height effect of the stud shear connectors. They provided an empirical equation to calculate the shear capacity of headed shear studs in composite beams with profiled steel sheeting. Grants expression for stud connector strength is given as Equation 2. Hawkins and Mitchell [22] performed a linear regression analysis and developed two separate equations of shear connectors shear strength due to concrete pull-out failure for $76 \mathrm{~mm}$ deck and $38 \mathrm{~mm}$ deck. In the Equation 3 , for $76 \mathrm{~mm}$ deck and $38 \mathrm{~mm}$ deck $\xi$ is 0.35 and 0.61 , respectively. $\lambda$ (factor dependent upon type of concrete) is ranging from 0.75 and 1.0 that depends on the density of concrete. Rambo-Roddenberry [5] carried out 92 push-out tests to study the behavior of headed stud shear connectors in composite beams with profiled steel sheeting perpendicular to the beam. He provided also a new strength prediction model, based on the strength prediction equations to calculate the shear capacity of headed shear studs. In his approaches, the strength prediction divided four parts which differ from each other to the $\mathrm{d} / \mathrm{t}$ ratio and stud height.

The design strength and stiffness of composite beams with profiled steel sheeting depends on the shear connection behavior. Because of the steel deck geometry of the composite beams with profiled steel sheeting the strength of the shear connectors may be reduced. An empirical expression for this reduction was developed by evaluating results of composite beam tests in many standards. 
The AISC [18], equation for the calculation of the design strength of headed stud shear connector in composite beams with profiled steel sheeting perpendicular to the steel beam is given Equation 4 . The $r_{1}$ (reduction factor), which should not be taken greater than 1.0, is a function of the deck geometry and the number of studs in a rib. Elastic modulus of concrete is $E_{c}=4700 \sqrt{f_{c}}$ according to the ACI [23] building code. In the BSI (BS 5950 Part 3) design strength of headed stud shear connector in composite beams with profiled steel sheeting perpendicular to the steel beam is determined by multiplying the values by reduction factor given as Equation 5. In the expression, if $\frac{h}{d} \geq 3$, $\alpha$ must be less than 1.0 for $\alpha=0.2\left(\frac{h}{d}+1\right)$, where $r_{2}$ is reduction factor $\left(r_{2} \leq 1.0\right)$. The design strength for EC4 [1] of the headed stud in composite beams with profiled steel sheeting perpendicular to the steel beam is similar to the AISC equations, except the constant 0.5 is changed to 0.29 in the equation, and the upper limit on this strength is $80 \%$ of the tensile strength of the stud. In the expression, if $3 \leq \frac{h}{d} \leq 4, \alpha$ is $\left(\frac{h}{d}-1\right)$ and $\alpha=1$ for $\frac{h}{d}>4$. The strength reduction factor $\left(r_{3}\right)$ is ranging from 1.0 to 0.6. Canadian Standards Association (CSA) [20], specification is the same equation as the one in the AISC [18] specification. According to the CSA, strength of headed stud shear connector depends on the depth of the rib given as Equation 7-1 and 7-2.

Table 1. A Review of the Regulations of Shear Capacity of Composite Beams

Model

Fisher [21]

Grant et al. [6]

Hawkins and

Mitchell [22]

AISC [18]

BSI BS 5950 [19]

EC 4 [1]

CSA [20]
Expression

$$
P_{\text {FISHER }}=0.36 \frac{b_{0}}{h_{p}} * 0.5 A_{s} \sqrt{f E_{c}}
$$

$$
P_{\text {GRANT }}=\frac{0.85}{\sqrt{N}}\left(\frac{b_{0}}{h_{p}}\right)\left[\left(\frac{h-h_{p}}{h_{p}}\right) 0.5 A_{s} \sqrt{f E_{c}}\right] \leq 0.5 A_{s} \sqrt{f E_{c}}
$$

$$
P_{B S 5950}=\left(0.25 r_{2} \alpha d^{2} \sqrt{0.8 f_{c} E_{c}}, \quad 0.6 r_{2} f_{u} \frac{\pi d^{2}}{4}\right) \mathrm{min}
$$

$$
P_{\text {AISC }}=\underbrace{\left(\frac{0.85}{\sqrt{N}}\left(\frac{b_{0}}{h_{p}}\right)\left[\left(\frac{h}{h_{p}}\right)-1.0\right]\right.}_{r_{1}} 0.5 A_{s} \sqrt{f E_{c}} \leq A_{s} f_{u}
$$

$$
P_{E C 4}=\left(0.29 r_{3} \alpha d^{2} \sqrt{f_{c} E_{c m}}, 0.8 r_{3} f_{u} \frac{\pi d^{2}}{4}\right) \min
$$

$P_{C S A}=\left(4.2 A_{c} \sqrt{f_{c}}, 0.5 A_{s} \sqrt{f_{c} E_{c}} \leq A_{s} f_{u}\right) \mathrm{min}$; for $76 \mathrm{~mm} \mathrm{deck}$

$P_{C S A}=\left(7.3 A_{c} \sqrt{f_{c}}, 0.5 A_{s} \sqrt{f_{c} E_{c}} \leq A_{s} f_{u}\right) \mathrm{min}$; for $38 \mathrm{~mm} \mathrm{deck}$ 


\section{GENETIC PROGRAMMING}

Genetic programming (GP) is an extension to Genetic Algorithms proposed by Koza [24]. Koza defines GP as a domain-independent problem-solving approach in which computer programs are evolved to solve, or approximately solve, problems based on the Darwinian principle of reproduction and survival of the fittest and analogs of naturally occurring genetic operations such as crossover (sexual recombination) and mutation. GP reproduces computer programs to solve problems by executing the following steps (Figure 4.) :

1) Generate an initial population of random compositions of the functions and terminals of the problem (computer programs).

2) Execute each program in the population and assign it a fitness value according to how well it solves the problem.

3) Create a new population of computer programs.

i) Copy the best existing programs (Reproduction)

ii) Create new computer programs by mutation.

iii) Create new computer programs by crossover (sexual reproduction).

iv) Select an architecture-altering operation from the programs stored so far.

4) The best computer program that appeared in any generation, the best-so-far solution, is designated as the result of genetic programming [24].

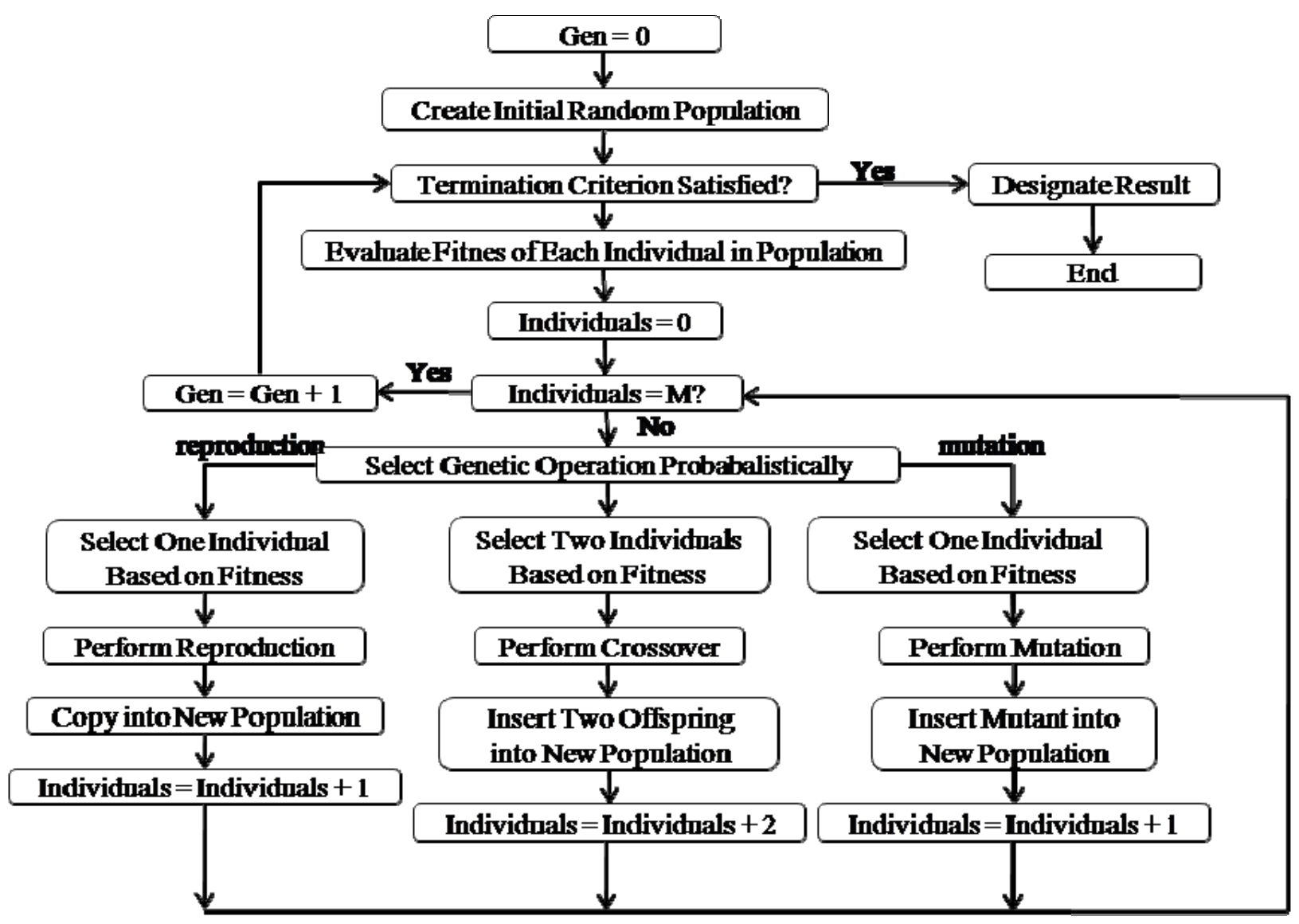

Figure 4. Genetic Programming Flowchart [24] 
Gene expression programming (GEP) software which is used in this study is an extension to GP that evolves computer programs of different sizes and shapes encoded in linear chromosomes of fixed length. The chromosomes are composed of multiple genes, each gene encoding a smaller sub-program. Furthermore, the structural and functional organization of the linear chromosomes allows the unconstrained operation of important genetic operators such as mutation, transposition, and recombination. One strength of the GEP approach is that the creation of genetic diversity is extremely simplified as genetic operators work at the chromosome level. Strength of GEP consists of its unique, multigenic nature which allows the evolution of more complex programs composed of several sub-programs. As a result GEP surpasses the old GP system in 100-10.000 times. [25-27].

The phenotype of GEP individuals consists of the same kind of diagram representations used by GP. However, these complex entities are encoded in simpler, linear structures of fixed length - the chromosomes. Thus, the main players in GEP are two entities: the chromosomes and the ramified structures or expression trees (ETs), being the latter the expression of the genetic information encoded in the former. The process of information decoding (from the chromosomes to the ETs) is called translation. And this translation implies obviously a kind of code and a set of rules. The genetic code is very simple: a one-to-one relationship between the symbols of the chromosome and the functions or terminals they represent. The rules are also very simple: they determine the spatial organization of the functions and terminals in the ETs and the type of interaction between sub-ETs in multigenic systems [26, 27].

In GEP there are therefore two languages: the language of the genes and the language of ETs and, in this simple replicator/phenotype system, knowing the sequence or structure of one, know the other. In nature, although the inference of the sequence of proteins given the sequence of genes and vice versa is possible, practically nothing is known about the rules that determine the three-dimensional structure of proteins. But in GEP thanks to the simple rules that determine the structure of ETs and their interactions, it is possible to infer exactly the phenotype given the sequence of a gene, and vice versa. This bilingual and unequivocal system is called Karva language [27].

\subsection{Solving a Simple Problem with GEP}

For each problem, the type of linking function, as well as the number of genes and the length of each gene, are a priori chosen for each problem. While attempting to solve a problem, one can always start by using a single-gene chromosome and then proceed by increasing the length of the head. If it becomes very large, one can increase the number of genes and obviously choose a function to link the sub-ETs. One can start with addition for algebraic expressions or for Boolean expressions, but in some cases another linking function might be more appropriate (like multiplication or IF, for instance). The idea, of course, is to find a good solution, and GEP provides the means of finding one very efficiently [25-27].

As an illustrative example consider the following case where the objective is to show how GEP can be used to model complex realities with high accuracy. So, suppose one is given a sampling of the numerical values from the curve (remember, however, that in real-world problems the function is obviously unknown):

$y=3 a^{2}+2 a+1$ 
over 10 randomly chosen points in the real interval $[-10,+10]$ and the aim is to find a function fitting those values within a certain error. In this case, a sample of data in the form of 10 pairs $\left(a_{i}, y_{i}\right)$ is given where $a_{i}$ is the value of the independent variable in the given interval and $y_{i}$ is the respective value of the dependent variable $\left(a_{i}\right.$ values: $-4.2605,-2.0437,-9.8317,-8.6491,0.7328$, $-3.6101,2.7429,-1.8999,-4.8852,7.3998$; the corresponding $y_{i}$ values can be easily evaluated). These 10 pairs are the fitness cases (the input) that will be used as the adaptation environment. The fitness of a particular program will depend on how well it performs in this environment [25-27].

There are five major steps in preparing to use gene expression programming. The first is to choose the fitness function. For this problem one could measure the fitness $f_{i}$ of an individual program $i$ by the following expression:

$$
f_{i}=\sum_{j=1}^{C_{t}}\left(M-\left|C_{(i, j)}-T_{j}\right|\right)
$$

where $M$ is the range of selection, $C_{(i, j)}$ the value returned by the individual chromosome $i$ for fitness case $j$ (out of $C_{t}$ fitness cases) and $T_{j}$ is the target value for fitness case $j$. If, for all $j, \mid C_{(i, j)}$ $T_{j} \mid$ (the precision) less than or equal to 0.01 , then the precision is equal to zero, and $f_{i}=f_{\max }=C_{t}{ }^{*} M$. For this problem, use an $M=100$ and, therefore, $f_{\max }=1000$. The advantage of this kind of fitness function is that the system can find the optimal solution for itself. However there are other fitness functions available which can be appropriate for different problem types [25-28].

The second step is choosing the set of terminals $T$ and the set of functions $F$ to create the chromosomes. In this problem, the terminal set consists obviously of the independent variable, i.e., $T=\{a\}$. The choice of the appropriate function set is not so obvious, but a good guess can always be done in order to include all the necessary functions. In this case, to make things simple, use the four basic arithmetic operators.

Thus, $F=\{+,-, *, /\}$. It should be noted that there many other functions that can be used.

The third step is to choose the chromosomal architecture, i.e., the length of the head and the number of genes.

The fourth major step in preparing to use gene expression programming is to choose the linking function. In this case we will link the sub-ETs by addition. Other linking functions are also available such as subtraction, multiplication and division.

And finally, the fifth step is to choose the set of genetic operators that cause variation and their rates. In this case one can use a combination of all genetic operators (mutation at $p_{m}=0.051$; IS and RIS transposition at rates of 0.1 and three transposons of length 1,2 , and 3; one-point and two-point recombination at rates of 0.3 ; gene transposition and gene recombination both at rates of $0.1)$.

To solve this problem, lets choose an evolutionary time of 50 generations and a small population of 20 individuals in order to simplify the analysis of the evolutionary process and not fill this text with pages of encoded individuals. However, one of the advantages of GEP is that it is capable of solving relatively complex problems using small population sizes and, thanks to the compact Karva notation; it is possible to fully analyze the evolutionary history of a run. A perfect solution can be found in generation 3 which has the maximum value 1000 of fitness. The sub-ETs codified by each gene are given in Figure 3. Note that it corresponds exactly to the same test fuction given above in Equation 8 [25-27]. 
Thus expressions for each corresponding Sub-ET can be given as follows:

$y=\left(a^{2}+a\right)+(a+1)+\left(2 a^{2}\right)=3 a^{2}+2 a+1$

\section{NUMERICAL APPLICATION}

In this study, GeneXproTools 4.0 [29] software package is used for GP modeling of shear capacity of composite beams with profiled steel sheeting. Among the experimental database, 10 tests were used as testing set and the remaining 36 test as training set for GP training. The proposed GP formula is an empirical equation based on the experimental database given in section 2 . In the proposed GP model, input parameters were selected based on previously published studies which are sheeting type (width of rib of the profiled steel sheeting, depth of the rib), stud dimensions (height and diameter), slab dimensions (width, depth and height), reinforcement in the slab and concrete compression strength. The ranges of variables in the experimental database where the proposed GP model will be valid are given in Table A.1. Related parameters of the GP training are presented in Table 2. Statistical parameters of the proposed GP model are given in Table 3. The performance of GP model vs. test results is shown in Figure 5. The entire database with corresponding experimental and GP results are given in Table A.1. The expression tree of the GP model is presented in Figure 6 where $\mathrm{d}_{0}, \mathrm{~d}_{1}, \mathrm{~d}_{2}, \mathrm{~d}_{3}, \mathrm{~d}_{4}$ and $\mathrm{d}_{5}$ correspond to $\mathrm{b}_{1}, \mathrm{~b}_{2}, \mathrm{~b}_{3}, \mathrm{~h}_{\mathrm{p}}, \mathrm{t}$ and $\mathrm{d}$ respectively. Constants shown in Figure 6 are $-8715,7765$ and -6405 respectively. After putting the constants, the final formulation for ultimate shear capacity of composite beams is obtained as follows:

$$
P=\left[\left(\sqrt[3]{\frac{h_{p}-b_{2}}{N}}+F_{u}-65.93+h+N-b_{3}\right) \times\left(\frac{d}{t}+d-8.72+\sqrt{\frac{A}{t}}\right) \times\left(\frac{b_{3}}{b_{3}-b_{1}+F_{u}-f_{c u}+d-b_{1}}\right)\right]
$$

Table 2. Parameters of GP Model

\begin{tabular}{lll}
\hline P1 & Function Set & $+,-,, /, \sqrt{ }, \ln$ \\
\hline P2 & Chromosomes & $30-200$ \\
\hline P3 & Head Size: & $2-6$ \\
\hline P4 & Number of Genes: & $1-4$ \\
\hline P5 & Linking Function: & Addition, Multiplication \\
\hline P6 & Fitness Function Error Type: & MAE, RMSE, Custom Function \\
\hline P7 & Mutation Rate: & 0,044 \\
\hline P8 & Inversion Rate: & 0,1 \\
\hline P9 & One-Point Recombination Rate: & 0,3 \\
\hline P10 & Two-Point Recombination Rate: & 0,3 \\
\hline P11 & Gene Recombination Rate: & 0,1 \\
\hline P12 & Gene Transposition Rate: & 0,1 \\
\hline
\end{tabular}


Table 3. Statistical Parameters of the Proposed GP Model

\begin{tabular}{llll}
\hline & Mean & COV & $\mathrm{R}^{2}$ \\
\hline GP Testing Set & 1.06 & 0.125 & 0.86 \\
\hline GP Training Set & 1.01 & 0.125 & 0.92 \\
\hline GP Total Set & 1.02 & 0.125 & 0.91 \\
\hline
\end{tabular}

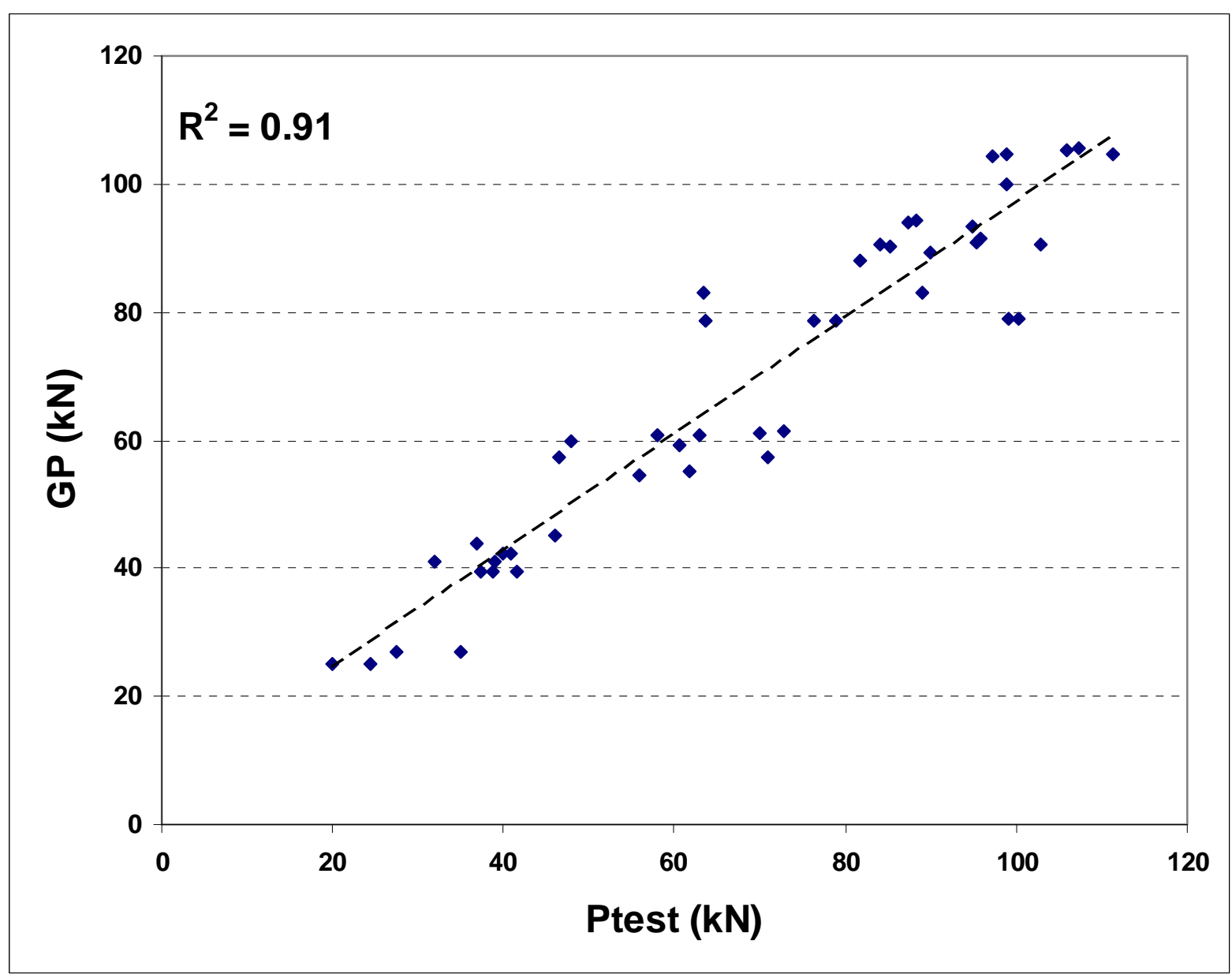

Figure 5. Performance of Test and GP Results 


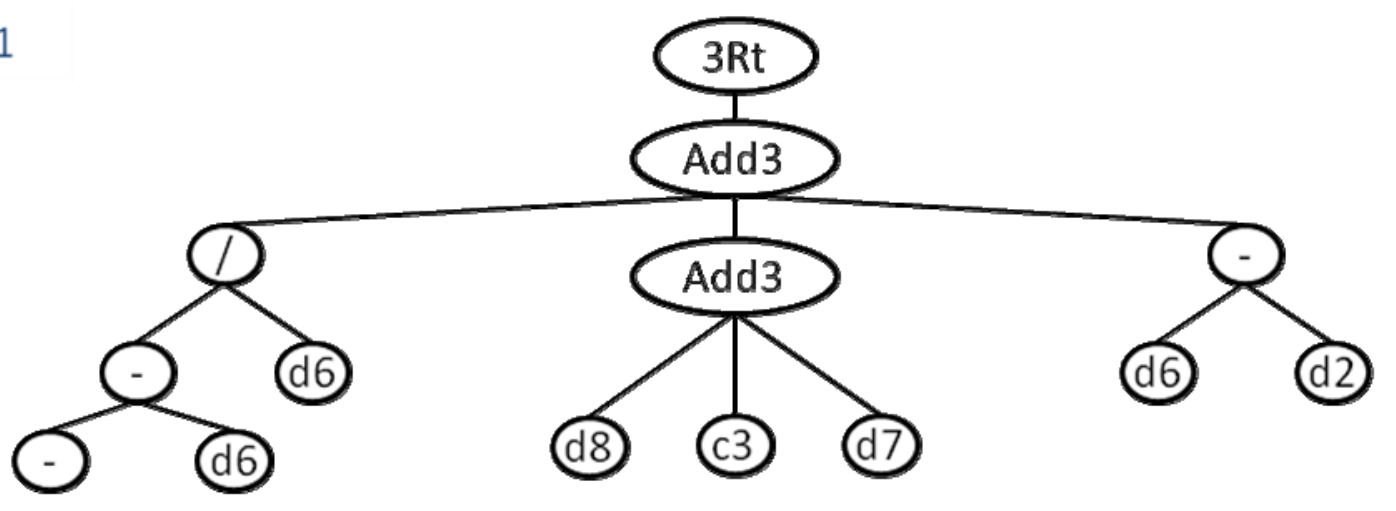

\section{Sub-ET 2}

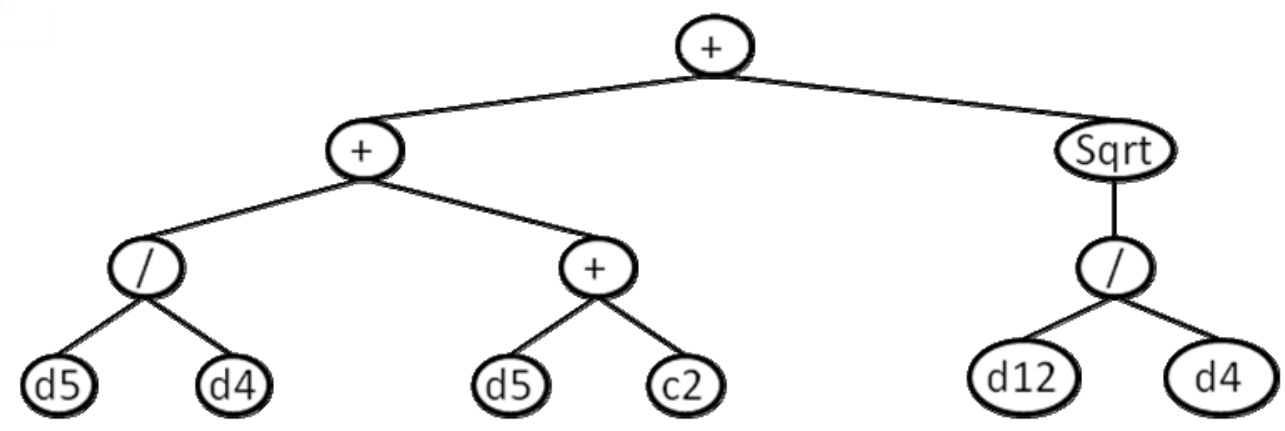

\section{Sub-ET 3}

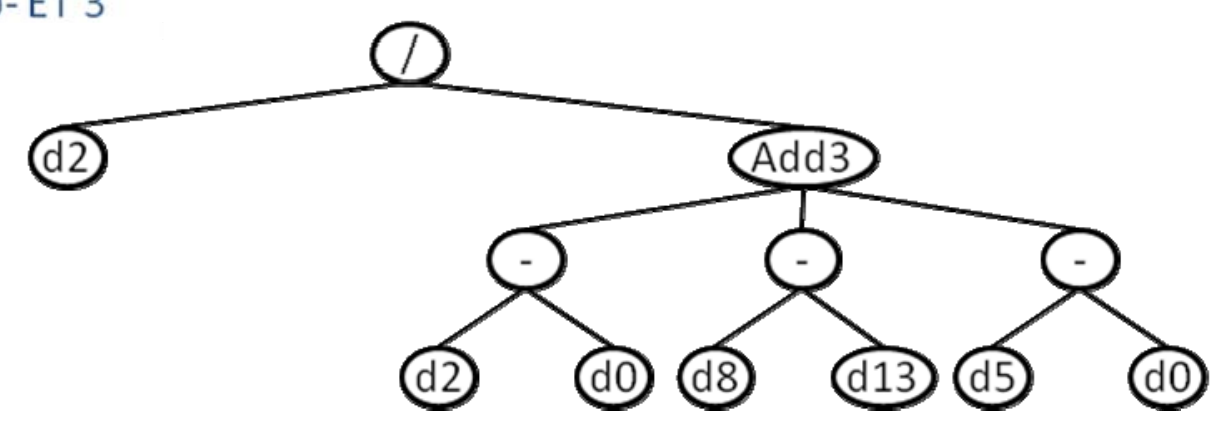

Figure 6. Expression Tree for Ultimate Shear Capacity of Composite Beams

The predicted ultimate shear strength values of the GP model are observed to be in very good agreement with the experimental data. The GP prediction accuracy is also compared with accuracies of code equations in Table 4. As seen the proposed GP model is by far more accurate than available design codes.

Table 4. Comparison of Accuracy of GP Model Versus Various Design Codes

\begin{tabular}{llllll}
\hline & GP & Paisc & Pec4 & Pbs & Pcsa \\
\hline Mean & 1.02 & 0.72 & 0.91 & 1.20 & 0.72 \\
\hline COV & 0.125 & 0.17 & 0.19 & 0.18 & 0.17 \\
\hline $\mathrm{R}^{2}$ & 0.91 & 0.79 & 0.78 & 0.79 & 0.79 \\
\hline
\end{tabular}


The prediction accuracy of various standards of building codes related to torsional strength of the beams for mentioned tested 46 specimens are presented in Table 4. As seen from Table 4., AISC 1999[18], Eurocode-4[1], BSI. BS 5950 [19] and CSA [20] shear capacity of composite beams expressions have the most powerful estimating capacity.

Although the estimation rate of design codes is nearly 79\%, GP model can estimate the shear capacity of shear studs in the composite beams with profiled steel sheeting such a high rate (91\%) GP and the other soft computing methods such as ANN, ANFIS...etc have more advantages than design codes formulas since they can train themselves in a comfortable way according to available data easily. Nevertheless, in design codes formulas all parameters that can change the result are not considered for some reason. Moreover, the maximum strength of materials and regulations are taken into consideration in the code's approaches. For instance, when calculating the shear capacity, the steel is assumed as to be yielded or the concrete reached the maximum compressive strength. While all materials could not run at full capacity during the experiments.

According to the results obtained from this study, GP can estimate the shearing capacity of shear studs in the composite beams with profiled steel sheeting in a very satisfactory way. But it is important to be known that the results can be changed by the selected data sets and using parameters in GP methods.

\section{CONCLUSION}

This study is a pioneer work that addresses the feasibility of GP as an alternative approach for the empirical formulation of shear capacity of shear studs in the composite beams with profiled steel sheeting for the first time. The proposed GP model is based on a wide range experimental database collected from the literature. The results of the proposed GP model are seen to be by far more accurate than current design codes and existing equations available in literature. Most of the design codes and equations available in literature are based on the regression analysis of predefined functions. However in the case of GP approach presented in this study, there is no predefined function to be considered. The GP approach generates various formulations and optimizes the best one that fits the experimental database best. The outcomes of this study are quite satisfactory which may serve GP approaches to widely used in further applications in the field of composite structures.

\section{NOTATION}

$A$

$A_{c}$

$A_{s}$

$B$

$b_{0}$

$b_{1}$

$b_{2}$

$b_{3}$

$D$

$d$

$E_{c}$

$E_{c m}$

$e$

$f_{c}$

Area of stud shank

Concrete pull-out failure surface area

The cross-sectional area of the headed stud shear connector

Width of composite concrete slab

Average width of concrete rib of the profiled steel sheeting

Smaller width of rib of the profiled steel sheeting

Larger width of rib of the profiled steel sheeting

Upper section of smaller width of rib of the profiled steel sheeting

Depth of composite concrete slab

Diameter of headed stud shear connector

Initial Young's modulus of concrete

Mean value of the secant modulus tabulated in the EC4

Distance from the center of the stud's longitudinal

Compressive cylinder strength of concrete 


$\begin{array}{ll}f_{c u} & \text { Compressive cube strength of concrete } \\ f_{u} & \text { Minimum specified tensile stress of the stud shear connector } \\ f_{y s} & \text { Yield stress of headed stud shear connector } \\ H & \text { Height of composite concrete slab } \\ h & \text { Height of the headed stud } \\ h_{p} & \text { Depth of the rib } \\ N & \text { Number of studs in one rib of the profiles steel sheeting } \\ n & \text { Number of studs subjected to similar displacements } \\ P_{A I S C} & \text { Design strength calculated using the American Specification } \\ P_{B S 5950} & \text { Design strength calculated using British Standard } \\ P_{C S A} & \text { Design strength calculated using Canadian Standards Association } \\ P_{E C 4} & \text { Design strength calculated using European Code } \\ P_{F I S H E R} & \text { Design strength calculated using Fisher formula } \\ P_{G R A N T} & \text { Design strength calculated using Grant formula in solid slab } \\ P_{O O L G A A R D} & \text { Design strength calculated using Oolgaard formula } \\ P_{P O S} & \text { Concrete pull-out strength of a stud in a composite slab } \\ P_{R R} & \text { Design strength calculated using Rambo-Roddenbery formula } \\ P_{S O L} & \text { Design strength calculated using Fisher formula in solid slab } \\ r & \text { Reduction factor } \\ r_{1} & \text { Reduction factor } \\ r_{2} & \text { Reduction factor } \\ r_{3} & \text { Reduction factor } \\ V_{c} & \text { Shear strength due to concrete pull-out failure (N) } \\ \lambda & \text { Factor dependent upon type of concrete } \\ t & \text { Profiled steel sheeting thickness }\end{array}$

\section{ACKNOWLEDGEMENT}

This research was supported by Gaziantep University Research project Unit and Selcuk University BAP Office (SU-BAP 2007/06201071). Some data were taken from the Master of Science Thesis of M.A. Köroğlu named "Usage of Earthquake Steel Bar as Shear Connection in Composite Slabs"

\section{REFERENCES}

[1] Eurocode 4, EN 1994-1-1:2004, "Design of Composite Steel and Concrete Structures", European Committee for Standardisation (CEN), 2004.

[2] Ellobody, E. and Young, B., "Performance of Shear Connection in Composite Beams with Profiled Steel Sheeting”, Journal of Constructional Steel Research, 2006, Vol. 62, No. 7, pp. 682-694.

[3] Ollgaard, J.G., Slutter, R.G., and Fisher, J.W., "Shear Strength of Stud Connectors in Lightweight and Normal-Weight Concrete", Engineering Journal, AISC, 1971, Vol. 8, No. 2, pp. 55-64.

[4] Veldanda, M.R. and Hosain, M.U., "Behavior of Perfobond Rib Shear connectors: Push-Out Tests", Canadian Journal of Civil Engineering, 1992, Vol. 19, No.1, pp. 1-10.

[5] Rambo-Roddenberry, M.D., "Behavior and Strength of Welded Stud Shear Connectors", $\mathrm{PhD}$ Dissertation, Department of Civil Engineering, Virgiana Politechnic Institute and State University, USA, 2002.

[6] Grant, J.A., Fisher, J.W. and Slutter, R.G., "Composite Beams with Formed Steel Deck", Engineering Journal, AISC, 1977, Vol. 14, No. 1, pp. 24-43. 
[7] Zellner, W., "Recent Designs of Composite Bridges and a New Type of Shear Connectors", Proceedings of the IABSE/ASCE Engineering Foundation Conference on Composite Construction, Henniker, N.H., pp. 240-252.

[8] Klaiber, F.W. and Wipe, T.J., "An Alternate Shear Connector for Composite Action”, Proc. Mid-continent Transportation Symposium 2000, Iowa State University, 2000.

[9] Valente, I. and Cruz, P.J.S., "Experimental Analysis of Perfobond Shear Connection between Steel and Lightweight Concrete", Journal of Constructional Steel Research, 2004, Vol. 60, No. 3-5, pp. 465-479.

[10] Galjaard, J.C. and Walraven, J.C., "Behavior of Shear Connector Devices for Lightweight Steel-Concrete Composite Structures-Results", Observations and Comparisons of Static Tests, 2000, pp. 221-230.

[11] Johnson, R.P. and Oehlers, D.J., "Analysis and Design for Longitudinal Shear in Composite T-Beams.” Proc. Instn Civ. Engrs, 1981, Part 2, Vol. 71, No. 4, pp. 989-1021.

[12] Köroğlu, M.A., "Usage of Earthquake Steel Bar as Shear Connection in Composite Slabs", MSc Thesis, Selçuk University, Konya Turkey, 2007 (In Turkish).

[13] Köroğlu, M.A. and Köken, A., "Load Bearing Capacity of Headed Studs in Composite Beams” 3th National Steel Structures Symposium, 8-10 October, 2009 - Gaziantep, Turkey (In Turkish).

[14] Köken, A. and Köroğlu, M.A., "An Experimental Study on the Usability of Earthquake Resistant Steel Bar as a Shear Connector in Composite Slabs", $10^{\text {th }}$ European Conference on Non-Destructive Testing 2010, 7-11 June, Moscow, Russia.

[15] http://www.corusconstruction.com/en/

[16] Lloyd, R.M. and Wright, H.D., "Shear Connection between Composite Slabs and Steel Beams", Journal of Constructional Steel Research, 1990, Vol. 15, No. 4, pp. 255-285.

[17] Kim, B., Wright, H.D. and Cairns, R., "The Behavior of Through-deck Welded Shear Connectors: An Experimental and Numerical Study", Journal of Constructional Steel Research, 2001, Vol. 57, No. 12, pp. 1359-1380.

[18] AISC, "Load and Resistance Factor Design Specification for Structural Steel Building", 1999, American Institute of Steel Construction, Chicago.

[19] BSI, BS 5950, Part 3: Section 3.1. "Code of Practice for Design of Simple and Continuous Composite Beams", 1990, British Standards Institution, London.

[20] CSA, "Steel Structures for Buildings - Limit State Design", 1984, Canadian Standards Association.

[21] Fisher, J.W., "Design of Composite Beams with Formed Metal Deck", Engineering Journal, AISC, 1970, Vol. 7, No.3, pp. 88-96.

[22] Hawkins, N.M. and Mitchell, D., "Seismic Response of Composite Shear Connections", Journal of Structural Engineering, ASCE, 1984, Vol. 110, No. 9, pp. 2120-2136.

[23] ACI, "Building Code Requirements for Structural Concrete and Commentary", 1999, American Concrete Institute, Detroit.

[24] Koza, J.R., "Genetic Programming: On the Programming of Computers by Means of Natural Selection”, Cambridge, MA: MIT Press, 1992.

[25] Ferreira, C., "Gene Expression Programming in Problem Solving", 6th Online World Conference on Soft Computing in Industrial Applications, September 10-24, 2001.

[26] Ferreira, C., "Gene Expression Programming: A New Adaptive Algorithm for Solving Problems", Complex Systems, 2001, Vol. 13, No. 2, pp. 87-129.

[27] Ireland, J.C., Baeten, M., Foster, J., Lutton, E. and Ryan, C., "Genetic Programming”, $5^{\text {th }}$ European Conference, 2002, EuroGP.

[28] Cevik, A., Arslan, M.H. and Köroglu, M.A., "Genetic-programming-based Modeling of RC Beam Torsional Strength" KSCE Journal of Civil Engineering, 2010, Vol. 14, No. 3, pp. 371-384.

[29] www.gepsoft.com 


\section{APPENDIX}

Table A.1. Database with corresponding experimental and GP results

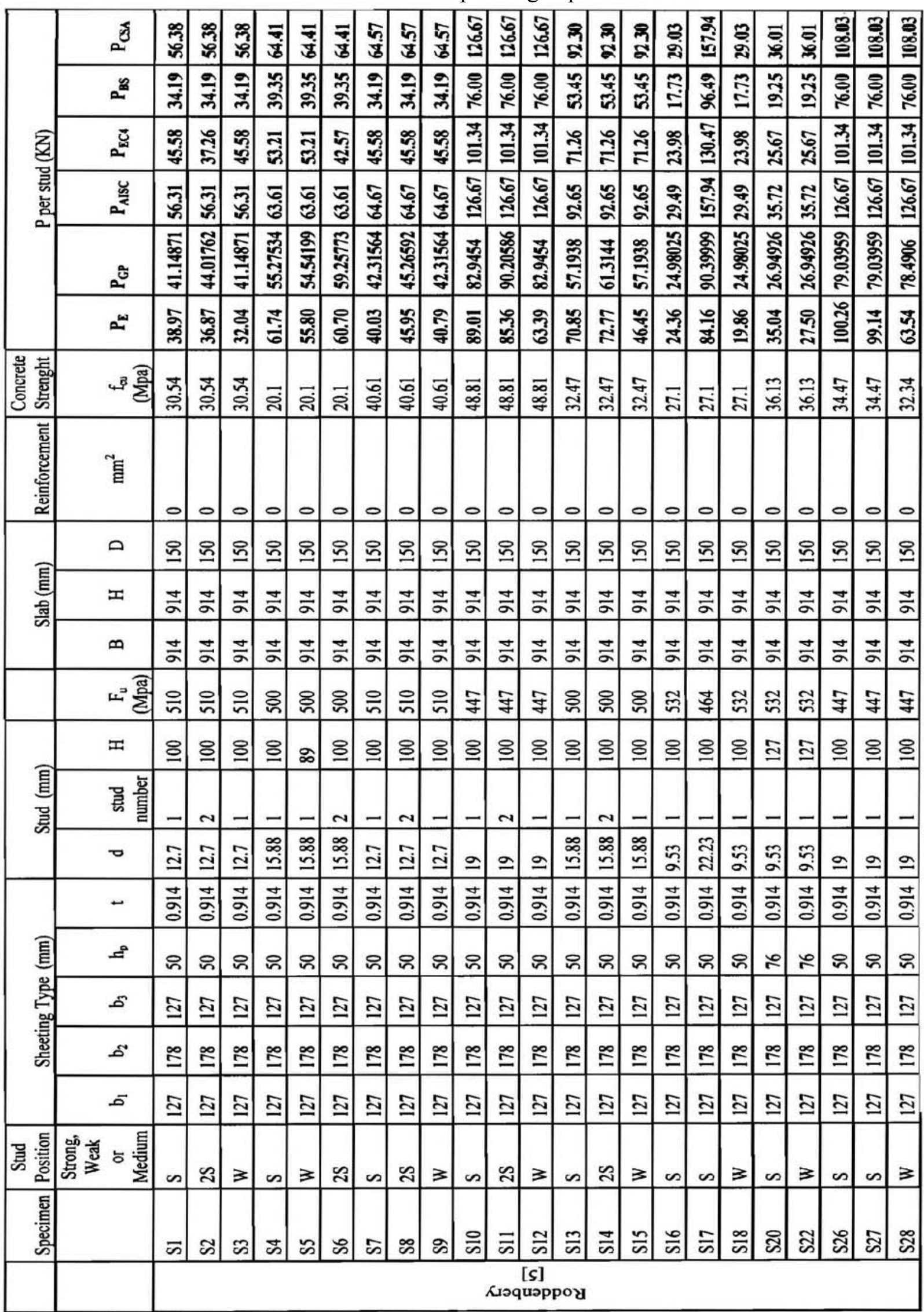




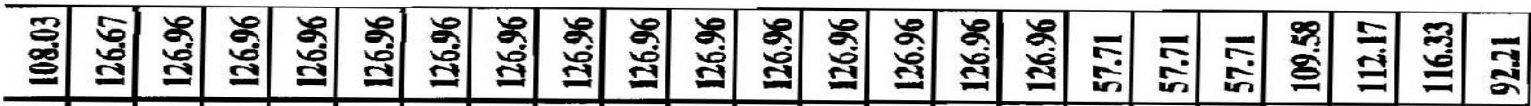

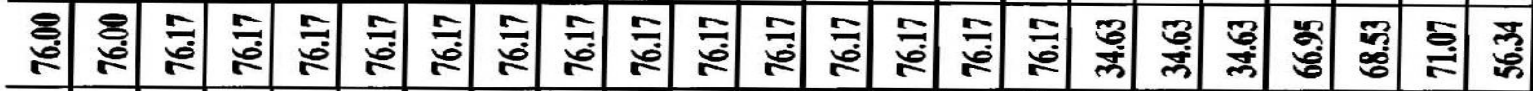

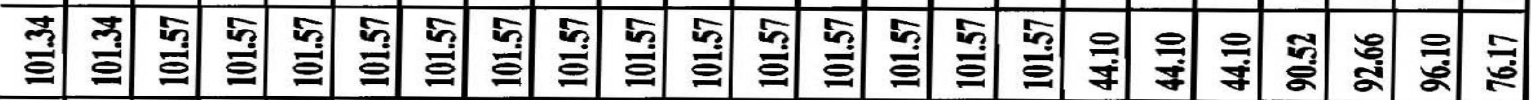

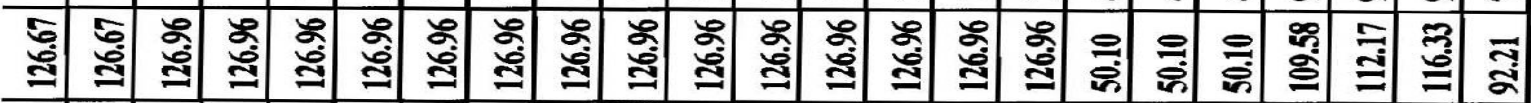 \\ 站 总

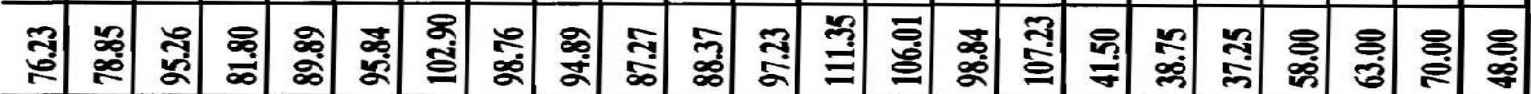

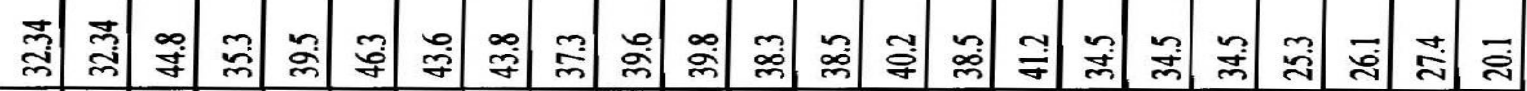

이

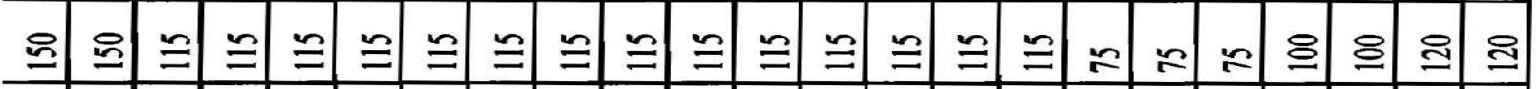

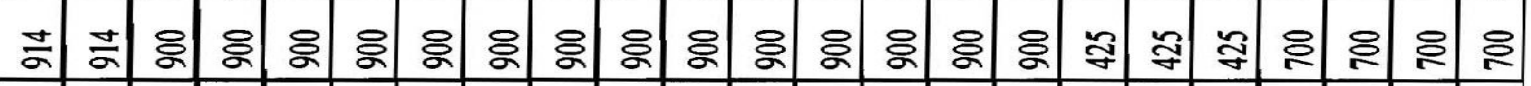

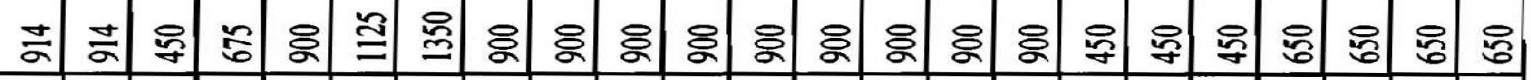

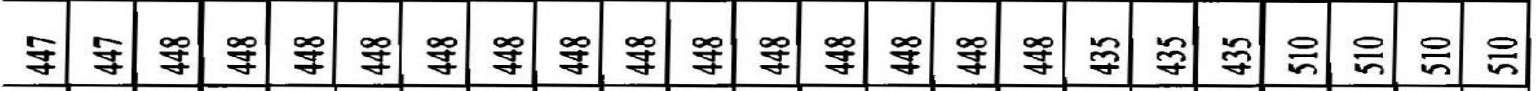

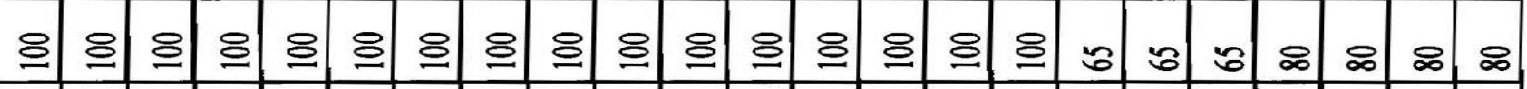

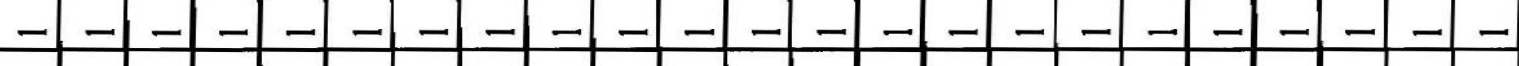

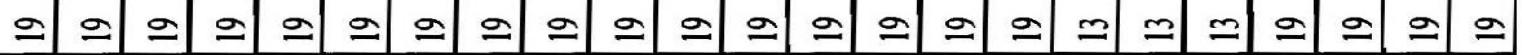

妾

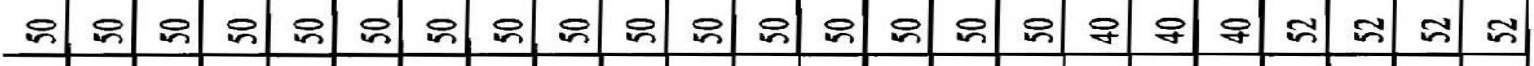

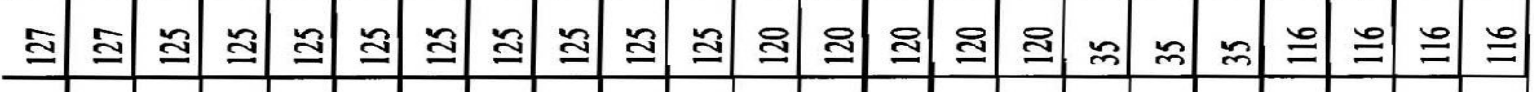

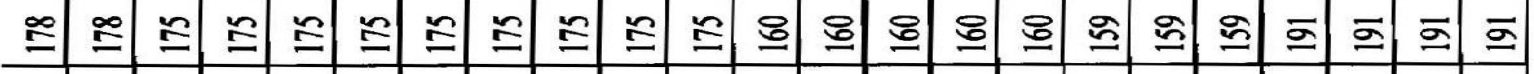

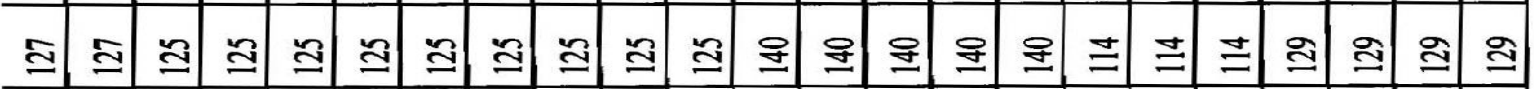

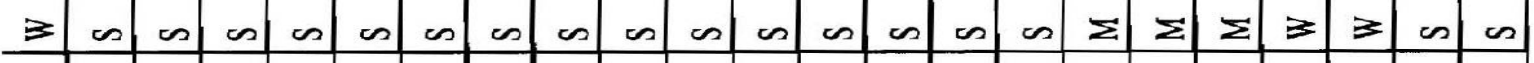
灾灾 